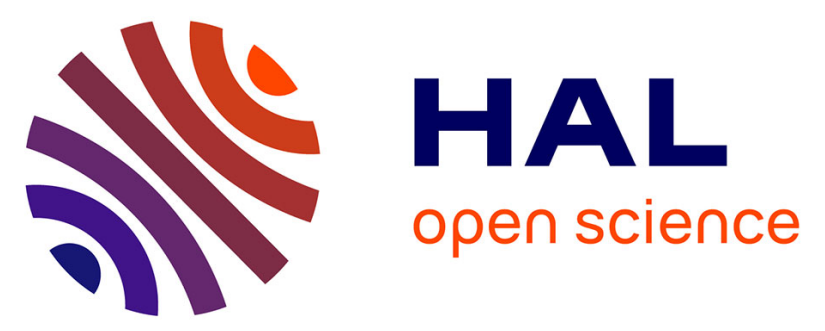

\title{
Combined Lung-Sound- and Reflux-Monitoring: A pilot study of a novel approach to detect nocturnal respiratory symptoms in Gastro-Oesophageal Reflux Disease (GERD)
}

Steffen Kunsch, Volker Gross, Albrecht Neesse, Christoph Nell, Keywan

Sohrabi, Thomas Gress, Volker Ellenrieder, Ulrich Köhler

\section{To cite this version:}

Steffen Kunsch, Volker Gross, Albrecht Neesse, Christoph Nell, Keywan Sohrabi, et al.. Combined Lung-Sound- and Reflux-Monitoring: A pilot study of a novel approach to detect nocturnal respiratory symptoms in Gastro-Oesophageal Reflux Disease (GERD). Alimentary Pharmacology and Therapeutics, 2011, 33 (5), pp.592. 10.1111/j.1365-2036.2010.04559.x . hal-00605687

\section{HAL Id: hal-00605687 https://hal.science/hal-00605687}

Submitted on 4 Jul 2011

HAL is a multi-disciplinary open access archive for the deposit and dissemination of scientific research documents, whether they are published or not. The documents may come from teaching and research institutions in France or abroad, or from public or private research centers.
L'archive ouverte pluridisciplinaire HAL, est destinée au dépôt et à la diffusion de documents scientifiques de niveau recherche, publiés ou non, émanant des établissements d'enseignement et de recherche français ou étrangers, des laboratoires publics ou privés. 


\begin{tabular}{l}
\hline Alimentary Pharmacology \\
\hline \& Therapeutics \\
\hline
\end{tabular}

\section{Combined Lung-Sound- and Reflux-Monitoring: A pilot study of a novel approach to detect nocturnal respiratory symptoms in Gastro-Oesophageal Reflux Disease (GERD)}

\begin{tabular}{|r|l|}
\hline Journal: & Alimentary Pharmacology \& Therapeutics \\
\hline Manuscript ID: & APT-0906-2010.R2 \\
\hline Wiley - Manuscript type: & Original Scientific Paper \\
\hline Author: & 06-Dec-2010 \\
\hline Complete List of Authors: & $\begin{array}{l}\text { Kunsch, Steffen; University of Marburg, Department of } \\
\text { Gastroenterology } \\
\text { Gross, Volker; University of Applied Sciences Giessen-Friedberg, } \\
\text { Department of Biomedical Engineering } \\
\text { Neesse, Albrecht; University of Marburg, Department of } \\
\text { Gastroenterology } \\
\text { Nell, Christoph; University of Marburg, Department of Pulmonary } \\
\text { Diseases } \\
\text { Sohrabi, Keywan; University of Applied Sciences Giessen-Friedberg, } \\
\text { Department of Biomedical Engineering } \\
\text { Gress, Thomas; UniversitÃxtsklinikum GieÃ Ÿen und Marburg, Klinik } \\
\text { für Innere Medizin; University of Marburg, Department of } \\
\text { Gastroenterology } \\
\text { Ellenrieder, Volker; University of Marburg, Department of } \\
\text { Gastroenterology } \\
\text { Köhler, Ulrich; University of Marburg, Department of Pulmonary } \\
\text { Diseases }\end{array}$ \\
\hline Keywords: & $\begin{array}{l}\text { GERD or GORD < Disease-based, X keyword = no topic , Y keyword } \\
\text { = no topic, Z keyword = no topic }\end{array}$ \\
\hline \hline
\end{tabular}

\section{SCHOLARONE ${ }^{\text {TH }}$




\title{
Combined Lung-Sound- and Reflux-Monitoring: A pilot study of a novel approach to detect nocturnal respiratory symptoms in Gastro-Oesophageal Reflux Disease (GERD)
}

\author{
S. Kunsch ${ }^{1^{*}}$, V. Gross ${ }^{3^{*}}$, A. Neesse ${ }^{1}$, A. K. Sohrabi ${ }^{3}$, C. Nell ${ }^{2}$, TM. Gress ${ }^{1}$, \\ V. Ellenrieder ${ }^{1^{* *}}$, U. Koehler ${ }^{2^{* *}}$
}

1. Department of Gastroenterology, Endocrinology and Metabolism, Faculty of Medicine, Philipps-University of Marburg, Germany.

2. Department of Pulmonary Diseases, Faculty of Medicine, Philipps-University of Marburg, Germany.

3. Department of Biomedical Engineering, University of Applied Sciences Giessen-Friedberg, Germany.

Corresponding Author:

Prof.Dr.T.M.Gress

Faculty of Medicine

Department of Gastroenterology, Endocrinology and Metabolism

Philipps-University of Marburg

Baldingerstr. 1

35043 Marburg

Germany

Tel.: ++ 4964215866460

Fax.: ++ 4964215868922

e-mail: gress@med.uni-marburg.de

* SK and VG contributed equally and should both be considered first authors

** UK and VE contributed equally and should both be considered last authors

This study was supported by a Research Grant of the University Medical Center Giessen and Marburg (UKGM) 


\section{ABSTRACT:}

Background and aims: Increased prevalence of respiratory symptoms has been commonly reported in patients with gastroesophageal reflux disease (GERD). Here, we introduce a novel Lung-Sound-Monitoring device that allows simultaneous measurement of both nocturnal respiratory symptoms and episodes of acidic and biliary refluxes. Methods: Nocturnal respiratory symptoms (coughing and wheezing) were continuously recorded in 20 healthy subjects and 30 reflux patients with respiratory symptoms in parallel to combined $\mathrm{pH}$-monitoring and Bilitec measurement. Results: Analysis could be completed in 20 healthy subjects and in 25 patients with reflux. A clear temporal correlation to reflux phases was detected in $49 \%$ of coughing and $41 \%$ of wheezing events, respectively. Moreover, $89 \%$ of the coughing and $100 \%$ of the wheezing events succeeded reflux episodes. Finally, the technique was capable of assessing a statistically significant difference between patients and controls regarding the occurrence of these symptoms. Conclusions: Our pilot study establishes the Lung-Sound-Monitoring system as a unique tool to objectively measure the temporal correlation between gastroesophageal reflux and the appearance of respiratory symptoms. It represents a useful technique to identify patients with respiratory symptoms due to reflux and therefore allows to determine and quantify the impact of therapeutic interventions such as antireflux therapy on respiratory symptoms. 


\section{Introduction:}

Gastro-oesophageal reflux disease (GERD) is caused by reflux of gastric acids and duodenal components such as bile acids into the oesophagus and represents one of the most common disorders in the industrialized world [1]. Interestingly, an increased prevalence of respiratory symptoms such as chronic coughing or bronchial asthma have been reported in association with GERD [2-7], in particular during the sleeping period [8-10]. However, an etiologic relationship of these two disease entities has not been corroborated [11]. Oesophageal-bronchial microaspiration and vagus nerve stimulation by refluxate with subsequent bronchial obstruction and hyperresponsiveness are pathophysiological mechanisms that have been hypothesized to be the cause of respiratory symptoms in GERD patients [12-17]. These concepts are further supported by clinical observations showing that respiratory symptoms alleviate or even disappear after surgical or medical therapy of GERD [18-21]. In contrast, there is also evidence that chronic coughing and wheezing caused by any type of bronchopulmonal disease can precipitate reflux events by increasing intraabdominal pressure, thus consecutively triggering passage of gastric contents into the oesophagus [22]. Controversially, respiratory symptoms of a large percentage of patients with chronic coughing or asthma do not respond favourably to proton pump inhibitor therapy [18;23-28].

Since the suspected mechanisms of disease as described above are diverse there is no level A evidence to support any type of treatment regimen, thus management of patients with suspected reflux-induced respiratory symptoms remains largely empirical $[11 ; 29]$. Consequently it is of major importance to develop an approach and technology reliably allowing to measure and quantify the occurrence of respiratory symptoms in association with the occurrence of acidic and biliary gastro-oesophageal reflux in a standardized and objective way. This is necessary to identify subgroups of 
patients showing a temporal association between reflux episodes and respiratory symptoms, which should help to determine the pathophysiological mechanism responsible for this association. Furthermore it would allow to identify patients that will benefit from medical or surgical treatment, and to monitor treatment efficacy. A large number of studies have investigated this potential association [30;31], however, methodological limitations mainly concerning the accurate and objective detection of respiratory symptoms reduce their validity. For instance, the use of event buttons or patient diaries for the recording of coughs is highly subjective and not possible during the sleeping period, when the majority of reflux-associated respiratory symptoms are supposed to occur [32]. Therefore, a new technical device is required that combines objective detection of respiratory symptoms with simultaneous measurement of reflux episodes.

Here, we introduce an outpatient Lung-Sound-Monitoring device capable to continuously record respiratory symptoms throughout the night and to measure acid (pH-monitoring) and biliary dominated (Bilitec Measurement) reflux events in parallel. For the first time, the two distinct respiratory symptoms "coughing" and "wheezing" can be objectively distinguished and precisely determined in temporal association with different types of gastro-oesophageal reflux.

The presented pilot study was conducted to proof the feasibility of this novel approach combining Lung-Sound-Monitoring with simultaneous measurement of acidic and biliary reflux in patients with respiratory symptoms. 


\section{Materials and Methods}

\section{Evaluation of healthy subjects}

Lung-Sound-Monitoring was performed in 20 healthy subjects prior to the recruitment of GERD patients to prove the feasibility and to evaluate normal frequency of nocturnal respiratory symptoms like coughing or wheezing. Individuals with the history of clinical symptoms of GERD, chronic pulmonary diseases or regular medication of any type were excluded. To evaluate a potential effect of the oesophageal catheter on the frequency of respiratory symptoms Lung-SoundMonitoring was performed twice in 8 out of the 20 healthy subjects. Throughout the first night the participants were evaluated without an oesophageal catheter, in the following night Lung-Sound Monitoring was repeated with an oesophageal $\mathrm{pH} / \mathrm{Bilitec}$ catheter in place.

\section{Patients and study protocol:}

30 patients were enrolled in this pilot study. All patients were referred to the outpatients department of the University of Marburg for suspected reflux disease. The pattern of clinical symptoms was evaluated with a questionnaire, specifically designed by our group [33]. The symptoms heartburn, regurgitation, chest pain, dysphagia, nocturnal coughing, wheezing, hoarseness and vomiting were graded according to severity into 1: not existing, 2: mild, 3: moderate and 4: severe. Only patients with typical clinical symptoms of a reflux disease and suspected respiratory symptoms like wheezing, nocturnal coughing or hoarseness within the last six month were enrolled. Patients with chronic pulmonary diseases (e.g. asthma or chronic obstructive bronchitis) or previous Gl-surgery, such as antireflux surgery or gastric resection were excluded. Standardised clinical work-up of patients included combined oesophageal $24 \mathrm{~h} \mathrm{pH}$-measurement and Bilitec $₫ 2000$ in combination with 
nocturnal Lung-Sound-Monitoring. Nocturnal Lung-Sound-Monitoring was performed at the patients' home and supervised by trained medical staff. Oesophageal manometry and gastroscopy were routinely performed in all patients to exclude oesophageal motility disorders or malignancy. If the patient was on acid suppression therapy this was withdrawn at least 7 days prior to the diagnostic procedures. The study protocols were approved by the local ethics committee of the University of Marburg.

\section{Lung-Sound-Monitoring}

Following CORSA criteria for standardisation of lung sound measurement [34] we developed a mobile device for long-time recording of lung sounds [35]. For validation purposes, we first recorded lung sounds of 40 selected patients with exacerbated chronic lung diseases and compared the measurements with those received by simultaneous auscultation through a trained physician. The appearance of the key respiratory symptoms wheezing and coughing were noted by the physician and compared with the detection of lung sounds by our device. Analysis of lung sounds revealed a sensitivity and specificity of $100 \%$ for both symptoms, respectively.

The Lung-Sound-Monitoring device system is displayed in Figure 1. Four air-coupled microphones are used to capture lung sounds. Two microphones are positioned on the basis of each lung, a further one is fixed over the trachea and the remaining microphone detects environmental sounds. Signals are filtered and subsequently amplified. Analogue filtering applied to the captured sound signal varies from $60 \mathrm{~Hz}$ (high-pass filter) to $2.500 \mathrm{~Hz}$ (low-pass filter). Analogue-to-digital converters are used with 16 bits for digitalisation, followed by storage on a computer. The analysis device allows the audio-visual interpretation of the recorded lung sounds. Two independent and specifically trained investigators analysed the recorded lung sounds and marked 


\section{$\underline{P H}$ Monitoring and measurement of Duodenal-Gastro-Oesophageal Reflux (DGER)}

\section{by Bilitec $(2000$ :}

Oesophageal $\mathrm{pH}$ monitoring was performed using an antimony $\mathrm{pH}$ electrode with a separate skin reference electrode (Medtronic, Germany) in an outpatient setting. All data were stored on a portable digital recorder (Digitrapper Mk III). Prior to each measurement, the $\mathrm{pH}$ probe was calibrated in standard buffer solutions of $\mathrm{pH} 7$ and 1. An episode of acid reflux was defined as a decrease of the oesophageal $\mathrm{pH}$ value below 4 for at least $10 \mathrm{~s}$. pH values below 4 for longer than $4 \%$ of the total $24 \mathrm{~h}$ period were classified as pathological.

The fiber-optic spectrophotometer Bilitec ${ }^{\circ} 2000$ was used to quantify DGER. The system consists of a miniaturised probe, which carries light signals into the oesophagus and back trough a plastic fiber-optic bundle. Two light emitting diodes (470 and $565 \mathrm{~nm}$ ) represent the source for the measurement of bilirubin. The portable photodiode system converts the light into electrical signal. After amplification, the signals are processed by an integrated microcomputer, which calculates the differences of the absorbence at 470 and $565 \mathrm{~nm}$. This value is directly proportional to the bilirubin concentration in the sample under study. Bilirubin absorbance is an established marker for DGER [36]. Prior to each measurement, the probe was calibrated in water. A significant episode of DGER was defined as an increase in oesophageal bilirubin absorbance $>0.14$ for at least $10 \mathrm{~s}$.

Bilirubin absorbance above 0.14 for longer than $4,6 \%$ of the total $24 \mathrm{~h}$ period was classified as pathological. A specialised diet was prescribed to exclude an 
interference with DGER measurement. Both, the $\mathrm{pH}$ - and the Bilitec-catheter were positioned $5 \mathrm{~cm}$ above the lower oesophageal sphincter. The exact position of the lower oesophageal sphincter was determined in all patients using oesophageal manometry.

\section{Analysis of data}

Our analysis software displays the results of the reflux measurements $(\mathrm{pH}-$ Monitoring and Bilitec 2000) and the detected respiratory symptoms in temporal association. Reflux events (acidic, biliary or combined) were automatically detected within a period 2 minutes before and after the occurrence of a respiratory symptom (Figure 3). Coughing and wheezing events with temporal association to reflux episodes were divided into those preceding or following reflux. To calculate statistical significance of the temporal association a Symptom Association Probability (SAP) analysis was done [37]. To assure the exact temporal synchronisation of lung sound and reflux measurement a synchronisation was routinely done at the beginning and the end of each measurement.

\section{Statistics:}

Data are presented as mean \pm S.D. unless stated otherwise. Two-sided WilcoxonMann-Whitney-Test was performed to compare the frequency of coughing and wheezing events in healthy subjects and patients. Fisher's exact test was used to calculate SAP. Statistical significance was accepted when $p$ was $<0.05$ (SAP>95\%). 


\section{Results:}

From January 2008 to January 201020 healthy controls and 30 patients with suspected GERD and respiratory symptoms as wheezing, nocturnal coughing or hoarseness were enrolled into this pilot study. In the patients group, 5 out of 30 patients had to be excluded due to incomplete Lung-Sound Monitoring ( $\mathrm{N}=2)$, incomplete reflux measurement $(\mathrm{N}=1)$ and occlusion of the Bilitec sensor by a bolus $(\mathrm{N}=2)$. The resulting 25 patients were completely analysed according to the study protocol.

Comparison between healthy controls and patients Lung-Sound Monitoring was performed in 20 healthy volunteers (14 male, 6 female, average of age 24.1 years +-2.1 ) to prove the feasibility of the technique and to determine the normal frequency of nocturnal coughing and wheezing. Coughing was detected in 6 out of the 20 healthy volunteers ( 11 events; average per night $0.55 \pm 0.9$; median 0; $Q_{75} 1.5 ; Q_{25}$ 0; max. 2; min. 0). Wheezing occurred in 2 out of the 20 healthy subjects (2 events; average per night 0.1 \pm 0.3 ; median 0; $Q_{75} 0 ; Q_{25} 0$; max. 1 ; min. 0 ). In the patient group ( $\mathrm{N}=25 ; 13$ male; 12 female; average of age 43 years \pm 19 ) coughing occurred in 19 (116 events; average per night 4.64 \pm 4.7 ; median 3; Q75 8; $Q_{25} 1$; max. 13; min. 0) and wheezing in 11 out of the 25 patients (39 events; average per night 1.56 \pm 2.8 ; median $0 ; Q_{75} 2 ; Q_{25} 0$; max. 9; min. 0). The statistical analysis of healthy volunteers $(n=20)$ compared to the patients $(n=25)$ resulted in a significant difference of both, coughing and wheezing $(p<0.05)$. These results are displayed in Figure 4.

To evaluate whether the presence of an oesophageal tube has irritating effects and causes and increase in the frequency of respiratory symptoms Lung-Sound 
Monitoring was repeated in the following night with a $\mathrm{pH} / \mathrm{Bilitec}$ catheter in place in 8 out of the 20 healthy volunteers. The statistical analysis revealed no significant difference between the measurement with and without the oesophageal tube, providing evidence that the oesophageal tube itself did not affect the frequency of nocturnal coughing and wheezing.

\section{Reflux measurement}

In all of the remaining 25 patients a combined 24 hour $\mathrm{pH}$ - and Bilitec-Measurement was performed in parallel to Lung-Sound Monitoring. Over the 24 hour period 21 out of the 25 patients exhibited increased reflux ( 8 combined, 6 isolated acidic and 7 isolated biliary reflux). The average fraction of time with a $\mathrm{pH}$ smaller than 4 within the 24 hours of measurement was $5.3 \%( \pm 3.5)$. The average time with a bilirubin absorbance greater than 0.14 was $14 \%( \pm 12.6)$. Overall 653 nocturnal reflux events were detected (Average 26.1 events per night, \pm 26.9 ) consisting of 108 combined, 230 acidic and 315 biliary reflux events.

\section{Coughing}

Our mobile device detected nocturnal coughs in 19 out of the 25 patients. A total number of 116 nocturnal coughs were identified. A temporal association between coughing and reflux was assumed if a reflux event occurred in a 2 minutes interval before or after each coughing event. 59 of the total number of coughing events $(51 \%)$ were considered independent of reflux, whereas 57 of 116 coughing events $(49 \%)$ showed a temporal association with reflux events. These 57 coughing events were associated with different types of reflux events: I. biliary reflux ( $N=37 ; 64 \%)$, II. acidic reflux $(\mathrm{N}=10 ; 18 \%)$ and III. combined reflux $(\mathrm{N}=10 ; 18 \%)$. 
For a more precise description of the exact temporal association of coughing and reflux we separated the resulting 57 coughing events with temporal association to reflux events into I. a reflux-coughing succession (RC-S) and II. a coughing-reflux succession (CR-S). The majority of coughing events showed a RC-S (51/57; 89\%). In $32(63 \%)$ of these coughing events the reflux event persisted until coughing started. In the remaining 19 events (37\%) reflux occurred in the 2 minutes interval before the cough but was already normalised when the patient started to cough. Only a small percentage of the 57 coughing events with a temporal correlation to reflux showed a coughing-reflux succession $(6 / 57 ; 11 \%)$.

To determine if the temporal correlation between coughing and reflux events is significant a symptom association probability (SAP) analysis was performed. In 9 out of the 19 patients with nocturnal coughing (47\%) a positive SAP analysis indicated a statistically significant temporal correlation between the respiratory symptom coughing and reflux events.

Notably, all patients showing a positive association in the SAP-analysis had a RC-S. Furthermore we analysed if the type of reflux had an influence on the results of the SAP-analysis. SAP-positive patients displayed biliary $(\mathrm{N}=6)$, acidic $(\mathrm{N}=1)$ and combined $(\mathrm{N}=2)$ reflux events (Figure 5$)$, thus indicating a predominance of biliary reflux.

\section{Wheezing}

In 11 out of 25 patients nocturnal wheezing was detected. A temporal association between wheezing and reflux was assumed if a reflux event occurred in a 2 minutes interval before or after a wheezing event. A total number of 39 nocturnal wheezing episodes were identified of which 23 (59\%) were considered to occur independent of reflux, whereas $16(41 \%)$ showed a temporal association with reflux events. These 
16 wheezing episodes were associated with different types of reflux events including biliary reflux $(\mathrm{N}=5 ; 31 \%)$, acidic reflux $(\mathrm{N}=9 ; 56 \%)$ and combined reflux $(\mathrm{N}=2 ; 13 \%)$. In analogy to the evaluation of coughing the detected wheezing episodes with temporal association to reflux events $(\mathrm{N}=16)$ were separated into a reflux-wheezing succession (RW-S) and a wheezing-reflux succession (WR-S). All wheezing episodes with temporal association to reflux showed a RW-S (16/16; 100\%). In 10 cases $(63 \%)$ the reflux event persisted until the occurrence of wheezing. In the remaining 6 cases (37\%) reflux occurred in the 2 minutes interval before the wheezing event but had already stopped before wheezing started. Interestingly, reflux in the 2 minutes period after wheezing was not observed.

To determine if the correlation between wheezing and reflux events is significant or only by chance a symptom association probability (SAP) analysis was performed. In 5 out of the 11 patients (45\%) with nocturnal wheezing, SAP analysis was positive (greater than 95\%) for wheezing episodes. All these patients had a RW-S and showed biliary $(\mathrm{N}=1)$, acidic $(\mathrm{N}=3)$ and combined $(\mathrm{N}=1)$ reflux events (Figure 6$)$, thus indicating a predominance of acidic reflux. 


\section{Discussion:}

An increased prevalence of respiratory symptoms has been commonly observed in reflux patients lending support to the plausible assumption that GERD might contribute to the occurrence of pulmonary disorders in certain patients. Unfortunately, however, methodological limitations of current available approaches to detect respiratory symptoms in GERD patients have hampered the design of clinical studies to address this issue and to demonstrate a clear temporal correlation between refluxevents and the presence of respiratory symptoms such as coughing and wheezing. Here, we present a novel and unique diagnostic tool that combines the simultaneous measurement of acidic and biliary reflux episodes with lung sounds recording in GERD patients. This novel device operates via air-coupled microphones that accurately detect lung sounds in a similar way as a doctor's stethoscope. By use of analogue filters and analogue-to-digital converters the device provides an audiovisual graphical display of the recorded lung sounds [35]. Subsequent computer analysis then allows to determine a putative temporal association of both events, reflux and respiratory symptoms.

In this pilot study, we exclusively focused on the detection of nocturnal lung sounds since (i) there is a growing body of epidemiological data suggesting that nocturnal reflux plays the major role in inducing respiratory symptoms [9], (ii) physiological alterations including slower gastric emptying, decreased saliva production and swallowing frequency as well as a diminished pressure in the upper oesophageal sphincter during night-time may facilitate aspiration of gastric contents into the upper airways [8] and (iii) multiple other stimuli such as exercise, temperature or air pollution may trigger respiratory symptoms during day time.

First, we aimed to evaluate the feasibility of the diagnostic approach to monitor lung sounds in parallel to acidic and biliary reflux in healthy subjects. As expected, 
the equipment used in an outpatient setting was well tolerated by all participants. Overall the healthy control group showed a significantly lower number of coughing and wheezing events as compared to GERD patients. To exclude that the presence of $\mathrm{pH}$-monitoring and Bilitec catheters in the oesophagus alone is sufficient to induce respiratory symptoms, we recorded the nocturnal lung sounds in a subgroup of healthy controls in the presence and in the absence of the $\mathrm{pH}$-monitoring/Bilitec catheters. This analysis revealed no significant differences between the frequency of respiratory symptoms in presence or absence of the oesophageal catheters.

Nocturnal coughing was detected in 19 out 25 GERD patients and almost half of the coughing events (49\%) coincided with reflux events. Interestingly, $89 \%$ of these coughing events were preceded by reflux whereas reflux was rarely detected after a cough. In contrast, nocturnal wheezing was only observed in 11 out of 25 patients and $41 \%$ of these wheezing events coincided with reflux events. Notably, $100 \%$ of these wheezing events were preceded by reflux episodes. At a first glance, it may appear surprising that the most frequently observed temporal association was that reflux events were followed by respiratory symptoms. This may be due to the selection of patients enrolled in our study. In contrast to previous studies primarily investigating patients with chronic coughing or asthma [30;31;37-39], we exclusively enrolled patients with typical symptoms of GERD and respiratory symptoms during the last 6 months. Therefore, the probability to detect patients in which coughing or wheezing provokes reflux was naturally rather low.

Symptom-associated probability (SAP) analysis was first introduced by Weusten et al. in 1994 [40] as a tool to estimate, if there is a real association between two observed events and thus to exclude that the association is caused only by chance. Using this SAP analysis on our data set, we identified 9 patients with values indicating a positive association for the reflux-coughing succession whereas for none 
of the patients with coughing-reflux succession a positive association could be shown. Furthermore the SAP analysis yielded a statistically significant correlation between reflux and wheezing for 5 out of 11 patients with wheezing events, which, as mentioned above, were all preceded by the reflux event. Although our pilot study does not have the power to draw general conclusions on the type of reflux inducing the corresponding respiratory symptoms, it is interesting to note that the majority of patients showing a positive association between coughing and reflux had predominantly biliary reflux events, whereas wheezing was more often preceded by acidic reflux. These observations are in line with previous data further supporting the hypothesis that non acidic components of the refluxate (such as biliary acids) may, at least in part, be responsible for reflux induced coughing, whereas obstructive respiratory symptoms such as wheezing may be primarily caused by acidic reflux $[38 ; 41 ; 42]$.

To conclude, we have developed a novel technical approach for simultaneously measuring lung sounds and acidic and biliary reflux episodes. The novelty of the presented device is the long time detection of all nocturnal respiratory symptoms with the quality of an auscultation with a stethoscope. Thus, this approach is superior, more reliable and objective than previously used techniques to detect respiratory symptoms. Using the mobile Lund-Sound-Monitoring device tool we could identify subgroups of patients with a clear temporal correlation between reflux and respiratory symptoms such as coughing and wheezing. These results support the hypothesis of a causative role of reflux episodes in triggering respiratory symptoms in GERD patients. Our study was primarily aimed at showing the feasibility of this new approach which can now be used for prospective studies to further investigate the mechanisms of reflux associated pulmonary diseases and to control for success under therapy. Follow up investigations of patients off and on proton pump inhibitors 
will show if initiation of a sufficient antireflux therapy has an impact on the objective frequency of respiratory symptoms.

Taken together this novel technology might be a useful tool for further scientific approaches but also capable to routinely identify a subgroup of patients with a causal relationship of GERD and pulmonary symptoms in the future.

\section{Reference List}

[1] Moayyedi P, Axon AT: Review article: gastro-oesophageal reflux disease--the extent of the problem. Aliment Pharmacol Ther 2005;22 Suppl 1:11-19.

[2] Vakil N, van Zanten SV, Kahrilas P, Dent J, Jones R: The Montreal definition and classification of gastroesophageal reflux disease: a global evidencebased consensus. Am J Gastroenterol 2006;101:1900-1920.

[3] Havemann BD, Henderson CA, El-Serag HB: The association between gastrooesophageal reflux disease and asthma: a systematic review. Gut 2007;56:1654-1664.

[4] Sontag SJ, Schnell TG, Miller TQ, Khandelwal S, O'Connell S, Chejfec G, Greenlee H, Seidel UJ, Brand L: Prevalence of oesophagitis in asthmatics. Gut 1992;33:872-876.

[5] Ford AC, Forman D, Moayyedi P, Morice AH: Cough in the community: a cross sectional survey and the relationship to gastrointestinal symptoms. Thorax 2006;61:975-979.

[6] Nordenstedt H, Nilsson M, Johansson S, Wallander MA, Johnsen R, Hveem $\mathrm{K}$, Lagergren J: The relation between gastroesophageal reflux and respiratory symptoms in a population-based study: the Nord-Trondelag health survey. Chest 2006;129:1051-1056.

[7] Irwin RS, Richter JE: Gastroesophageal reflux and chronic cough. Am J Gastroenterol 2000;95:S9-14.

[8] Fass R, Achem SR, Harding S, Mittal RK, Quigley E: Review article: supraoesophageal manifestations of gastro-oesophageal reflux disease and the role of night-time gastro-oesophageal reflux. Aliment Pharmacol Ther 2004;20 Suppl 9:26-38.

[9] Gislason T, Janson C, Vermeire P, Plaschke P, Bjornsson E, Gislason D, Boman G: Respiratory symptoms and nocturnal gastroesophageal reflux: a population-based study of young adults in three European countries. Chest 2002;121:158-163. 
[10] Sontag SJ, O'Connell S, Miller TQ, Bernsen M, Seidel J: Asthmatics have more nocturnal gasping and reflux symptoms than nonasthmatics, and they are related to bedtime eating. Am J Gastroenterol 2004;99:789-796.

[11] Galmiche JP, Zerbib F, Bruley d, V: Review article: respiratory manifestations of gastro-oesophageal reflux disease. Aliment Pharmacol Ther 15-32008;27:449-464.

[12] Tuchman DN, Boyle JT, Pack AI, Scwartz J, Kokonos M, Spitzer AR, Cohen S: Comparison of airway responses following tracheal or esophageal acidification in the cat. Gastroenterology 1984;87:872-881.

[13] Jack Cl, Calverley PM, Donnelly RJ, Tran J, Russell G, Hind CR, Evans CC: Simultaneous tracheal and oesophageal $\mathrm{pH}$ measurements in asthmatic patients with gastro-oesophageal reflux. Thorax 1995;50:201-204.

[14] Wu DN, Yamauchi K, Kobayashi H, Tanifuji Y, Kato C, Suzuki K, Inoue H: Effects of esophageal acid perfusion on cough responsiveness in patients with bronchial asthma. Chest 2002;122:505-509.

[15] Singh V, Aggarwal V, Bansal S, Nijhawan S, Chaudhary N: Effect of intraesophageal acid instillation on airway reactivity in patients with asthma. $J$ Assoc Physicians India 2000;48:601-602.

[16] Vincent D, Cohen-Jonathan AM, Leport J, Merrouche M, Geronimi A, Pradalier A, Soule JC: Gastro-oesophageal reflux prevalence and relationship with bronchial reactivity in asthma. Eur Respir J 1997;10:2255-2259.

[17] Ing AJ, Ngu MC, Breslin AB: Pathogenesis of chronic persistent cough associated with gastroesophageal reflux. Am J Respir Crit Care Med 1994;149:160-167.

[18] Kiljander TO, Salomaa ER, Hietanen EK, Terho EO: Gastroesophageal reflux in asthmatics: A double-blind, placebo-controlled crossover study with omeprazole. Chest 1999;116:1257-1264.

[19] Field SK, Sutherland LR: Does medical antireflux therapy improve asthma in asthmatics with gastroesophageal reflux?: a critical review of the literature. Chest 1998;114:275-283.

[20] Littner MR, Leung FW, Ballard ED, Huang B, Samra NK: Effects of 24 weeks of lansoprazole therapy on asthma symptoms, exacerbations, quality of life, and pulmonary function in adult asthmatic patients with acid reflux symptoms. Chest 2005;128:1128-1135.

[21] Field SK, Gelfand GA, McFadden SD: The effects of antireflux surgery on asthmatics with gastroesophageal reflux. Chest 1999;116:766-774.

[22] Moote DW, Lloyd DA, McCourtie DR, Wells GA: Increase in gastroesophageal reflux during methacholine-induced bronchospasm. J Allergy Clin Immunol 1986;78:619-623. 
[23] Ours TM, Kavuru MS, Schilz RJ, Richter JE: A prospective evaluation of esophageal testing and a double-blind, randomized study of omeprazole in a diagnostic and therapeutic algorithm for chronic cough. Am J Gastroenterol 1999;94:3131-3138.

[24] Mathew JL, Singh M, Mittal SK: Gastro-oesophageal reflux and bronchial asthma: current status and future directions. Postgrad Med J 2004;80:701705.

[25] Field SK: Gastroesophageal reflux and respiratory symptoms. Chest 1999;116:843.

[26] Kiljander TO, Harding SM, Field SK, Stein MR, Nelson HS, Ekelund J, Illueca M, Beckman O, Sostek MB: Effects of esomeprazole $40 \mathrm{mg}$ twice daily on asthma: a randomized placebo-controlled trial. Am J Respir Crit Care Med 155-2006;173:1091-1097.

[27] Gibson PG, Henry RL, Coughlan JL: Gastro-oesophageal reflux treatment for asthma in adults and children. Cochrane Database Syst Rev 2003;CD001496.

[28] Mastronarde JG, Anthonisen NR, Castro M, Holbrook JT, Leone FT, Teague WG, Wise RA: Efficacy of esomeprazole for treatment of poorly controlled asthma. N Engl J Med 9-4-2009;360:1487-1499.

[29] Gaude GS: Pulmonary manifestations of gastroesophageal reflux disease. Ann Thorac Med 2009;4:115-123.

[30] Harding SM, Guzzo MR, Richter JE: 24-h esophageal pH testing in asthmatics: respiratory symptom correlation with esophageal acid events. Chest 1999;115:654-659.

[31] Avidan B, Sonnenberg A, Schnell TG, Sontag SJ: Temporal associations between coughing or wheezing and acid reflux in asthmatics. Gut 2001;49:767-772.

[32] Paterson WG, Murat BW: Combined ambulatory esophageal manometry and dual-probe $\mathrm{pH}$-metry in evaluation of patients with chronic unexplained cough. Dig Dis Sci 1994;39:1117-1125.

[33] Kunsch S, Neesse A, Linhart T, Steinkamp M, Fensterer H, Adler G, Gress TM, Ellenrieder V: Impact of pantoprazole on duodeno-gastro-esophageal reflux (DGER). Z Gastroenterol 2009;47:277-282.

[34] Sun XQ, Cheetham BM, Evans KG, Earis JE: Estimation of analogue prefiltering characteristics for CORSA standardisation. Technol Health Care 1998;6:275-283.

[35] Gross V, Reinke C, Dette F, Koch R, Vasilescu D, Penzel T, Koehler U: Mobile nocturnal long-term monitoring of wheezing and cough. Biomed Tech (Berl) 2007;52:73-76. 
[41] Zerbib F, Roman S, Ropert A, des Varannes SB, Pouderoux P, Chaput U, Mion F, Verin E, Galmiche JP, Sifrim D: Esophageal pH-impedance monitoring and symptom analysis in GERD: a study in patients off and on therapy. Am J Gastroenterol 2006;101:1956-1963.

[42] Tutuian R, Mainie I, Agrawal A, Adams D, Castell DO: Nonacid reflux in patients with chronic cough on acid-suppressive therapy. Chest 2006;130:386391. 
Figure 1: Configuration of the novel Lung-Sound Monitoring device. 4 air-coupled microphones are used to capture lungs sounds. Analog-to-digital converters are used with 16 bits for digitalisation, followed by storage on a computer (A). 2 microphones are placed on the basis of each lung, 1 microphone is fixed over the trachea and the remaining microphone detects environmental sounds $(B)$.

Figure 2: Audio-visual analysis of lung sounds. The typical pattern of normal lung sound, coughing and wheezing is displayed. A: environmental sounds, T: trachea, L1: Left lung basis, L2: Right lung basis.

Figure 3: Computerized analysis of the simultaneous measurements of $\mathrm{pH}$, biliary reflux in correlation to coughing events. As an example a coughing event (blue arbour) is displayed in temporal association with a combined reflux event $(\mathrm{pH}<4$ and bilirubin absoption $>0.14$ ).

Figure 4: Number of coughing and wheezing events per night. HV (healthy volunteers; $\mathrm{N}=20$ ) and PG (patients group; $\mathrm{N}=25$ ). The values are displayed in median $(x), 75$ and 25 quartile $(\square)$, minimum $(\perp)$ and maximum $(T)$. The statistical analysis revealed a significant difference between the frequency of coughing and wheezing in $\mathrm{HV}$ and $P G\left(p<0.05^{\star}\right)$.

Figure 5: Flow diagram for detection of nocturnal coughing in the study population. SAP analysis was performed for each individual.

Figure 6: Flow diagram for the detection of nocturnal wheezing in the study population. SAP analysis was performed in each individual 
Figure 1: Configuration of the novel Lung-Sound Monitoring device. 4 air-coupled microphones are used to capture lungs sounds. Analog-to-digital converters are used with 16 bits for digitalisation, followed by storage on a computer (A). 2 microphones are placed on the basis of each lung, 1 microphone is fixed over the trachea and the remaining microphone detects environmental sounds

(B). 
Figure 2: Audio-visual analysis of lung sounds. The typical pattern of normal lung sound, coughing and wheezing is displayed. A: environmental sounds, T: trachea, L1: Left lung basis, L2: Right lung basis. 
Figure 3: Computerized analysis of the simultaneous measurements of $\mathrm{pH}$, biliary reflux in correlation to coughing events. As an example a coughing event (blue arbour) is displayed in temporal association with a combined reflux event $(\mathrm{pH}<4$ and bilirubin absoption $>0.14)$. 
Figure 4: Number of coughing and wheezing events per night. HV (healthy volunteers; $N=20$ ) and PG (patients group; $N=25)$. The values are displayed in median $(x), 75$ and 25 quartile $(\square)$, minimum $(\perp)$ and maximum $(T)$. The statistical analysis revealed a significant difference between the frequency of coughing and wheezing in HV and PG $\left(p<0.05^{*}\right)$. $1016 \times 762 \mathrm{~mm}(72 \times 72$ DPI $)$ 


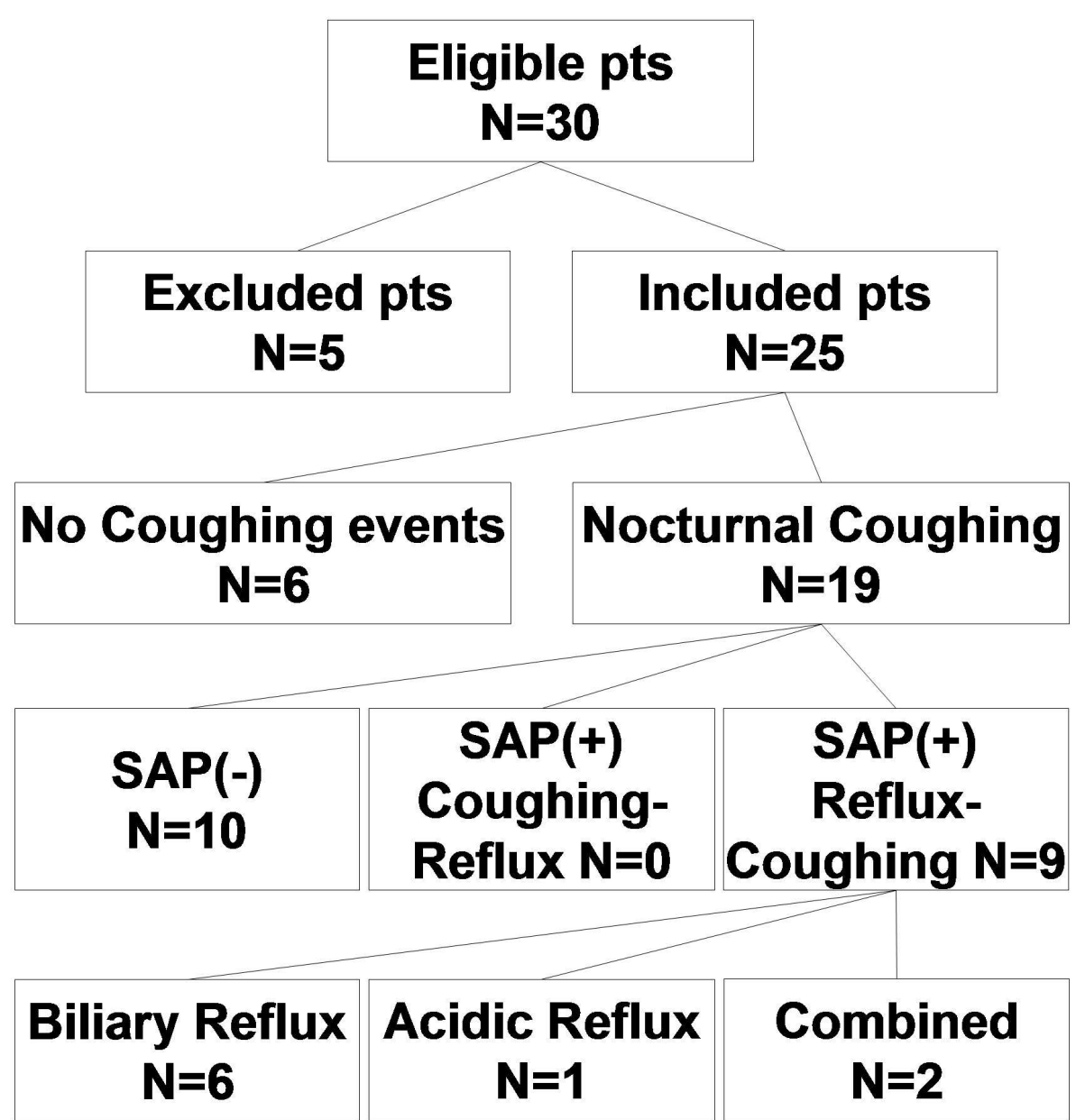

Figure 5: Flow diagram for detection of nocturnal coughing in the study population. SAP analysis was performed for each individual. $662 \times 673 \mathrm{~mm}(72 \times 72 \mathrm{DPI})$ 


\section{Biliary Reflux Acidic Reflux Combined $\mathrm{N}=1$ $\mathbf{N}=\mathbf{3}$ $\mathbf{N}=\mathbf{1}$}

Figure 6: Flow diagram for the detection of nocturnal wheezing in the study population. SAP analysis was performed in each individual. $658 \times 671 \mathrm{~mm}(72 \times 72 \mathrm{DPI})$ 